\title{
3D Finite Element Analysis of Drilling of Ti-6Al-4V Alloy
}

\author{
Y. Su, D.D. Chen, L. Gong \\ College of Mechanical Engineering \\ Jiangsu University of Science and Technology \\ China
}

\begin{abstract}
Drilling is an important machining process. A 3D FE model of drilling titanium alloys is developed using commercial finite element software DEFORM 3D. Simulations are carried out under different feed rates and drilling speeds to investigate the effect of drilling parameters on machining performance. The simulation results indicate the influence of machining parameters on drilling force, torque, and maximum tool temperature. The optimum drilling parameters are also recommended for drilling of Ti-6Al-4V according to the FE simulations.
\end{abstract}

Keywords-drilling ; finite element analysis; model; Ti-6Al$4 \mathrm{~V}$; drilling force; torque; maximum tool temperature

\section{INTRODUCTION}

With the development of machinery industry, higher requirements are put forward for the product quality and material properties. Drilling is a very important step throughout the machining process. In the past, a lot of experiments need to be conducted to obtain a series of related data during the drilling studies, which brings about huge raw materials consumption. Finite element method can make up this shortcoming. Finite element simulation can not only save the raw materials but also improve the accuracy of results. Furthermore, finite element analysis can also obtain the measured data which is difficult to obtain in experiment. Nowadays some scholars have studied drilling process based on the finite element simulation technology. For instance, F. Klocke et al. [1] introduced a three dimensional thermomechanical coupled finite element model for drilling AISI 4150 quenched and tempered steel by using carbide gun drills with two different diameters to predict the cutting forces as well as the temperature in gun drilling process. Y.B. Guo et al. $[2,3]$ investigated the burr formation using FE analysis of $3 \mathrm{D}$ drilling. O. Isbilir et al. [4] developed a 3D finite element model of drilling process using commercial finite element software ABAQUS/Explicit, and studied the effect of feed rate on thrust force, torque and burr height. The results indicate that the established FE model of drilling can predict changes in machining performance with respect to drilling parameters.

In this paper, a 3D finite element model of drilling of titanium alloys is first constructed, and then simulations are conducted under different drilling speeds and feed rates in order to analyze and compare the influence of drilling parameters on drilling force, torque and temperature.

\section{Finite ELEMENT Modelling Details}

\section{A. Geometric Model and Element Meshing}

Drill is a kind of complex cutting tool. Fig. 1. shows the geometry of drill. The geometry parameters of drill used in the model are given in table 1 . The workpiece is created as a cylinder in this study, whose diameter and height are $16 \mathrm{~mm}$ and $10 \mathrm{~mm}$, respectively. And there is a centering hole on the top surface of workpiece, whose depth is set at $1.1 \mathrm{~mm}$. Fig. 2. shows the geometric model of drilling process.

The drill and workpiece are divided into 25,000 and 35,000 grids, respectively. Pre-cutting region of workpiece is further subdivided so as to obtain a high simulation accuracy. Fig. 3. shows the mesh of workpiece and drill.

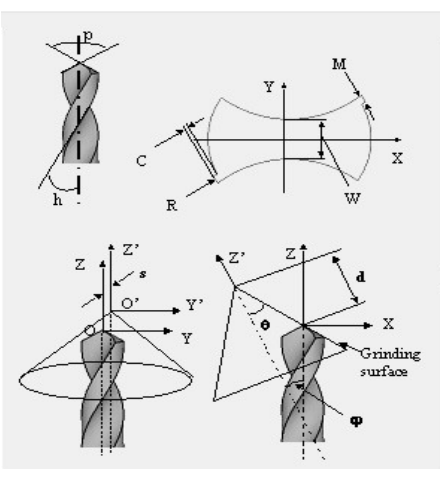

FIGURE I. DRILL GEOMETRY.

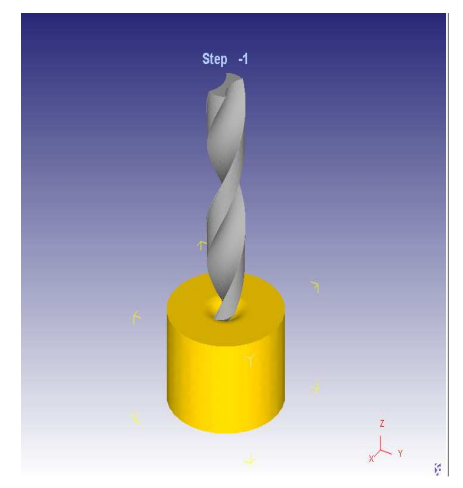

FIGURE II. GEOMETRIC MODEL. 
TABLE I. TOOL GEOMETRY PARAMETERS

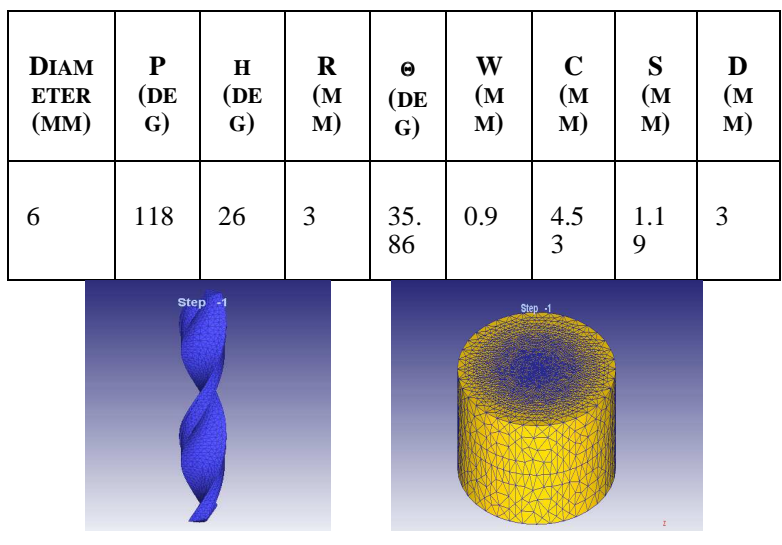

(a) Drill

FIGURE III. MESH OF WORKPIECE AND DRILL.

\section{B. Material Properties}

Carbide (WC) is selected as the material of drill and Ti$6 \mathrm{Al}-4 \mathrm{~V}$ is selected as the material of workpiece in this model. A classical Johnson-Cook model is selected as flow stress model of workpiece. This model can be represented by the following expression:

$$
\sigma=\left(A+B \varepsilon^{n}\right)\left(1+C \ln \frac{\dot{\varepsilon}}{\dot{\varepsilon}_{0}}\right)\left[1-\left(\frac{T-T_{r}}{T_{m}-T_{r}}\right)^{m}\right]
$$

where $\varepsilon_{\text {is }}$ the plastic strain, $\dot{\varepsilon}$ is the strain rate (s-1), $\dot{\varepsilon}_{0}$ is the reference plastic strain rate $(\mathrm{s}-1), \mathrm{T}$ is the temperature of workpiece $\left({ }^{\circ} \mathrm{C}\right), \mathrm{Tm}$ is the melting temperature of the workpiece $\left({ }^{\circ} \mathrm{C}\right), \mathrm{Tr}$ is the room temperature $\left({ }^{\circ} \mathrm{C}\right)$. Coefficient $\mathrm{A}$ is the yield strength (MPa), B is the hardening modulus (MPa), $\mathrm{C}$ is the strain rate sensitivity coefficient, $\mathrm{n}$ is the hardening coefficient and $\mathrm{m}$ is the thermal softening coefficient. The Johnson-Cook parameter values of Ti-6Al-4V are presented in table 2 [5].

\section{TABLE II. JOHNSON-COOK PARAMETER VALUES OF TI-6AL-4V ALLOY}

\begin{tabular}{ccccc}
\hline $\begin{array}{c}\boldsymbol{A} \\
(\mathbf{M P a})\end{array}$ & $\begin{array}{c}\boldsymbol{B} \\
(\mathbf{M P a})\end{array}$ & $\boldsymbol{C}$ & $\boldsymbol{n}$ & $\boldsymbol{m}$ \\
\hline 782.7 & 498.4 & 0.028 & 0.28 & 1 \\
\hline
\end{tabular}

\section{Simulation Conditions}

In the simulation, the workpiece is fixed in all directions. The drill rotates around $\mathrm{Z}$ axis and moves down along $\mathrm{Z}$ axis at the same time. The initial temperature and convection heat transfer coefficient of environment are set at $20^{\circ} \mathrm{C}$ and 0.02 $\mathrm{N} / \mathrm{sec} / \mathrm{mm} /{ }^{\circ} \mathrm{C}$, respectively. As far as the friction between tool and chip is concerned, a constant shear stress model is used and the friction factor is set equal to 0.6. The drilling speed $v_{\mathrm{c}}$ is set at $9.42,11.3$ and $13.19 \mathrm{~m} / \mathrm{min}$. The feed rate $f$ is set at $0.08,0.12$ and $0.16 \mathrm{~mm} / \mathrm{rev}$. Thus, 9 simulations are performed. The total simulation step is set at 10000 for each simulation.

\section{RESULTS AND DISCUSSION}

\section{A. Influence of Drilling Parameters on Drilling Force}

Drilling force not only determines the power consumption of drilling but also directly affects the cutting heat generated during the drilling process. Figs. 4. and 5. show the variation of axial force ( $\mathrm{Z}$ load) with time for different feed rates and drilling speeds, respectively. It can be seen that drilling force increases when the drill cuts into Ti-6Al-4V alloy, and then reaches a steady value. After that, it fluctuates in a certain range.

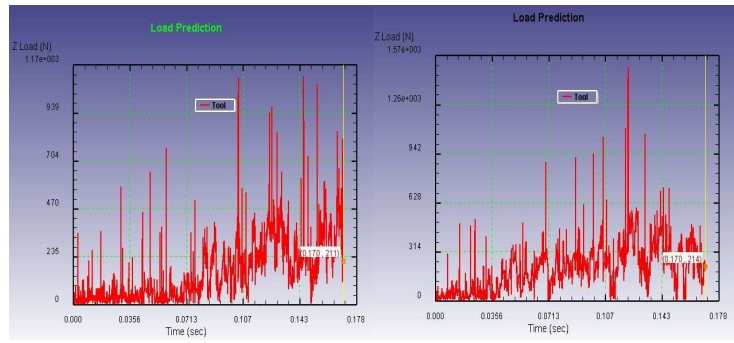

(a) $f=0.08 \mathrm{~mm} / \mathrm{rev}$

(b) $f=0.12 \mathrm{~mm} / \mathrm{rev}$

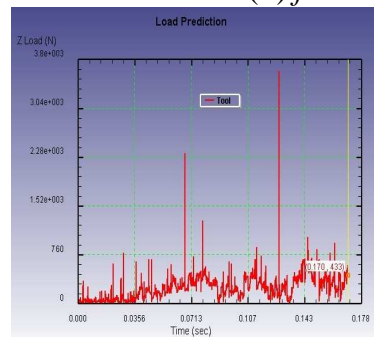

(c) $f=0.16 \mathrm{~mm} / \mathrm{rev}$

FIGURE IV. AXIAL FORCE AGAINST TIME UNDER DIFFERENT FEED RATES $(\mathrm{VC}=9.42 \mathrm{M} / \mathrm{MIN})$.

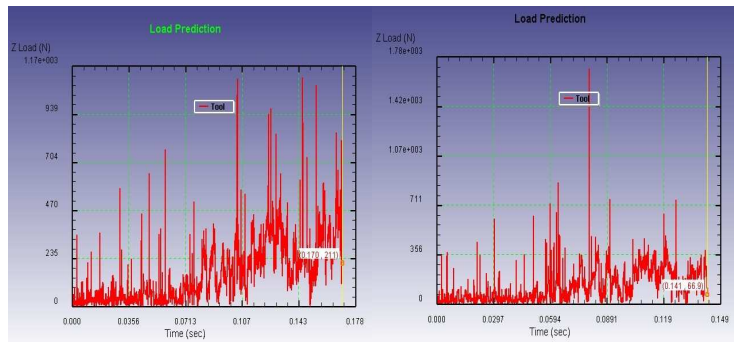

(a) $v_{\mathrm{c}}=9.42 \mathrm{~m} / \mathrm{min}$

(b) $v_{\mathrm{c}}=11.3 \mathrm{~m} / \mathrm{min}$

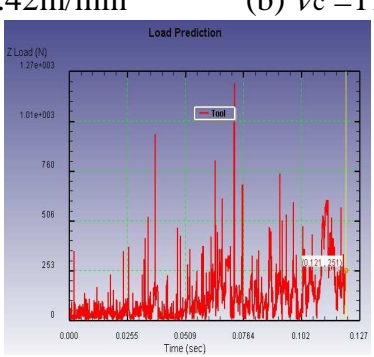

(c) $v_{\mathrm{c}}=13.19 \mathrm{~m} / \mathrm{min}$

FIGURE V. AXIAL FORCE AGAINST TIME UNDER DIFFERENT DRILLING SPEEDS ( $\mathrm{F}=0.08 \mathrm{MM} / \mathrm{REV})$

Figs. 6. and 7. show the variation of drilling force with drilling speed and feed rate obtained from simulation, 
respectively. As shown in fig. 6 , when the feed rate remains at $0.08 \mathrm{~mm} / \mathrm{rev}$, the drilling force decreases with the increase of drilling speed. And it increases with the increase of drilling speed when the feed rate remains at $0.12 \mathrm{~mm} / \mathrm{rev}$ and 0.16 $\mathrm{mm} / \mathrm{rev}$. Meanwhile, according to fig. 7, drilling force increases with the increase of feed rate, especially at a high drilling speed $(13.19 \mathrm{~m} / \mathrm{min})$. The lowest drilling force can be obtained at the feed rate of $0.08 \mathrm{~mm} / \mathrm{rev}$ and the drilling speed of $13.19 \mathrm{~m} / \mathrm{min}$. By comparing fig. 6. with fig. 7., it can be found that drilling force increases more rapidly with increasing the feed rate, indicating that feed rate has a more significant effect on drilling force than drilling speed.

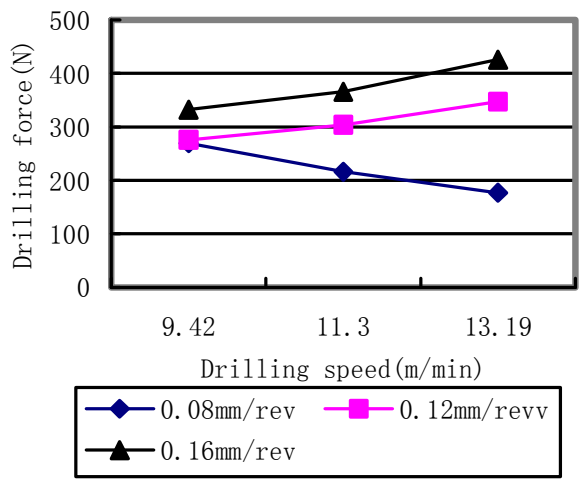

FIGURE VI. VARIATION OF DRILLING FORCE WITH DRILLING SPEED FOR VARIOUS FEED RATES.

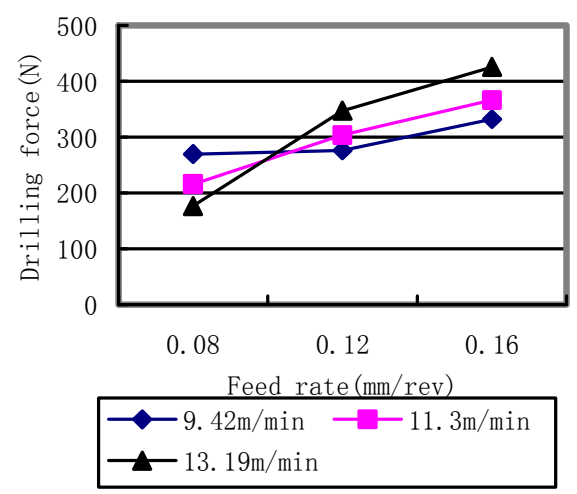

FIGURE VII. VARIATION OF DRILLING FORCE WITH FEED RATE FOR VARIOUS DRILLING SPEEDS.

\section{B. Influence of Drilling Parameters on Tool Temperature}

The predicted distribution of temperatures in the drill for different feed rates and drilling speeds are shown in figs. 8. and 9 , respectively. The maximum temperatures are indicated in each distribution. As shown in figs. 8. and 9, the maximum tool temperature appears in the vicinity of main cutting edge. Besides it, there is also high temperature in the chisel edge of drill.

Fig. 10. shows the variation of maximum tool temperature with drilling speed for different feed rates obtained from simulation. At the feed rates of 0.08 and $0.12 \mathrm{~mm} / \mathrm{rev}$, maximum tool temperature increases with increasing drilling speed from $9.42 \mathrm{~m} / \mathrm{min}$ to $11.3 \mathrm{~m} / \mathrm{min}$. Further increase in drilling speed results in a little change in maximum tool temperature. However, at the feed rate of $0.16 \mathrm{~mm} / \mathrm{rev}$, maximum tool temperature increases continuously with increasing drilling speed from $9.42 \mathrm{~m} / \mathrm{min}$ to $13.19 \mathrm{~m} / \mathrm{min}$. Fig. 11. shows the variation of maximum tool temperature with feed rate for different drilling speeds obtained from simulation. By comparing fig. 10. with fig. 11., it can be seen that the increase in maximum tool temperature resulting from increasing feed rate are more obvious than that resulting from increasing drilling speed.

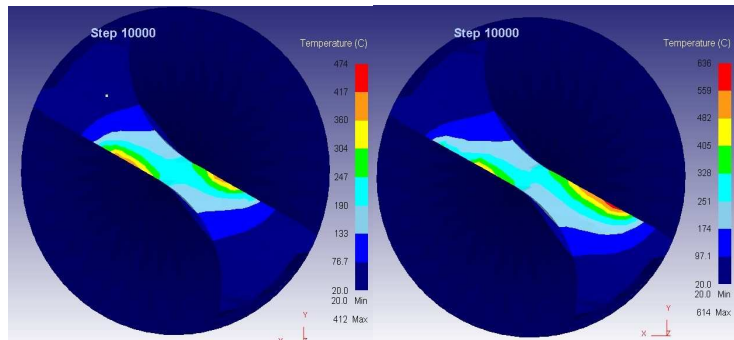

(a) $f=0.08 \mathrm{~mm} / \mathrm{rev}$ (b) $f=0.12 \mathrm{~mm} / \mathrm{rev}$

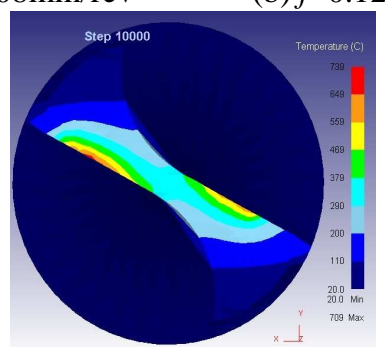

(c) $f=0.16 \mathrm{~mm} / \mathrm{rev}$

FIGURE VIII. PREDICTED TEMPERATURE DISTRIBUTION OF DRILL $(\mathrm{VC}=9.42 \mathrm{M} / \mathrm{MIN})$.

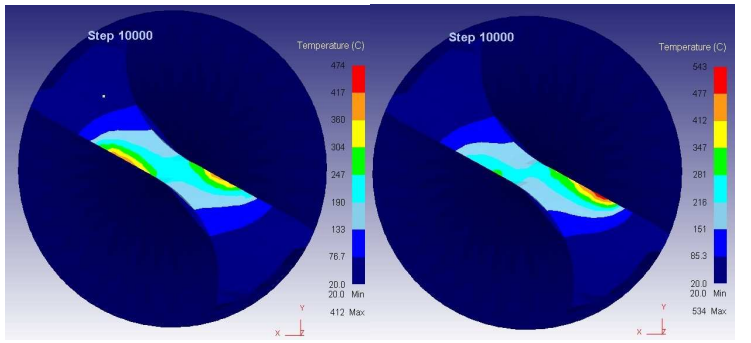

(a) $v_{\mathrm{c}}=9.42 \mathrm{~m} / \mathrm{min}$

(b) $v_{\mathrm{c}}=11.3 \mathrm{~m} / \mathrm{min}$

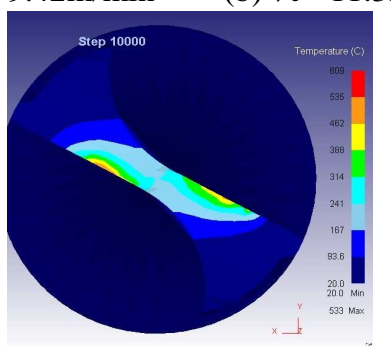

(c) $v_{\mathrm{c}}=13.19 \mathrm{~m} / \mathrm{min}$

FIGURE IX. PREDICTED TEMPERATURE DISTRIBUTION OF DRILL ( $\mathrm{F}=0.08 \mathrm{MM} / \mathrm{REV})$. 


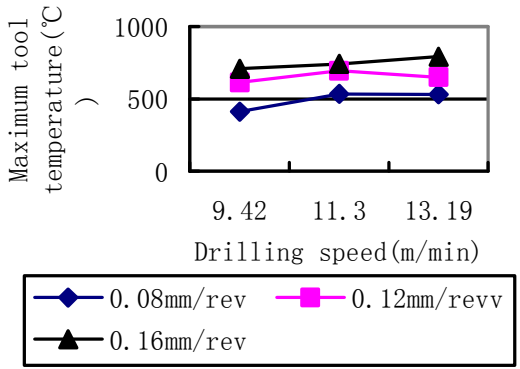

FIGURE X. VARIATION OF MAXIMUM TOOL TEMPERATURE WITH DRILLING SPEED FOR DIFFERENT FEED RATES.

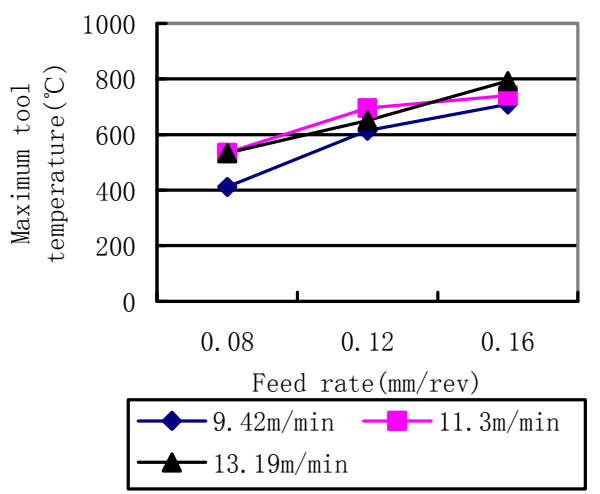

FIGURE XI. : VARIATION OF MAXIMUM TOOL TEMPERATURE WITH FEED RATE FOR DIFFERENT DRILLING SPEEDS.

\section{Influence of Drilling Parameters on Torque}

Drilling torque is an important parameter for drill design. Excessive torque will lead to the fracture of drill. Figs. 12. and 13. show drilling torque against time for different feed rates and drilling speeds, respectively. As shown in figs. 12. and 13, the trend of drilling torque against time is similar with that of drilling force against time.

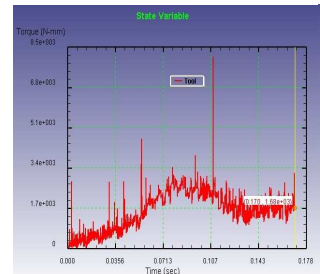

(a) $f=0.08 \mathrm{~mm} / \mathrm{rev}$

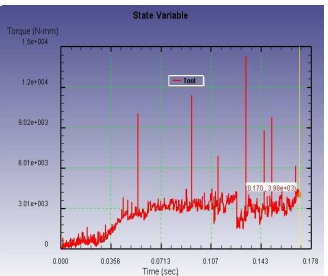

(b) $f=0.12 \mathrm{~mm} / \mathrm{rev}$

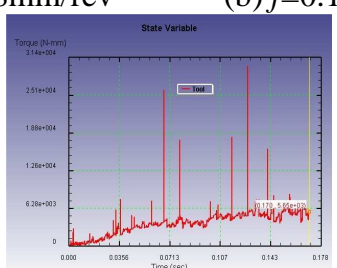

(c) $f=0.16 \mathrm{~mm} / \mathrm{rev}$

FIGURE XII. TORQUE AGAINST TIME UNDER DIFFERENT FEED RATES $(\mathrm{VC}=9.42 \mathrm{M} / \mathrm{MIN})$

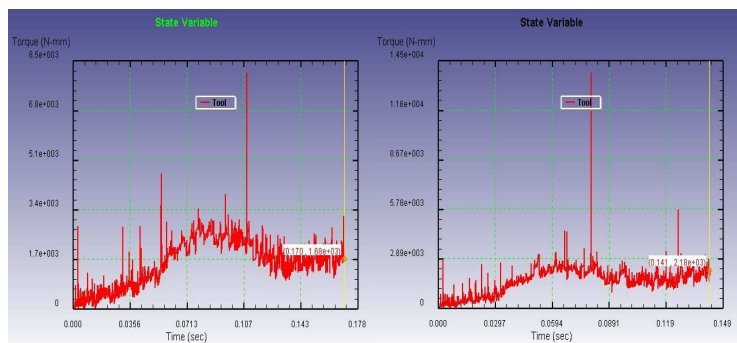

(a) $v_{\mathrm{c}}=9.42 \mathrm{~m} / \mathrm{min}$

(b) $v_{\mathrm{c}}=11.3 \mathrm{~m} / \mathrm{min}$

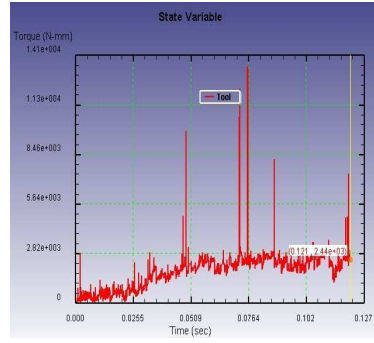

(c) $v_{\mathrm{c}}=13.18 \mathrm{~m} / \mathrm{min}$

FIGURE XIII. TORQUE AGAINST TIME UNDER DRILLING SPEEDS (F=0.08MM/REV).

Figs. 14. and 15. show the variation of drilling torque with drilling speed and feed rate obtained from simulation, respectively. It is illustrated in fig. 14. that drilling torque decreases with the increase of drilling speed when feed rate remains at $0.16 \mathrm{~mm} / \mathrm{rev}$, and it increases slowly with the increase of drilling speed when feed rate remains at 0.08 $\mathrm{mm} / \mathrm{rev}$ and $0.12 \mathrm{~mm} / \mathrm{rev}$. It can be seen from fig. 15 . that drilling torque increases rapidly with the increase of feed rate, regardless of drilling speed.

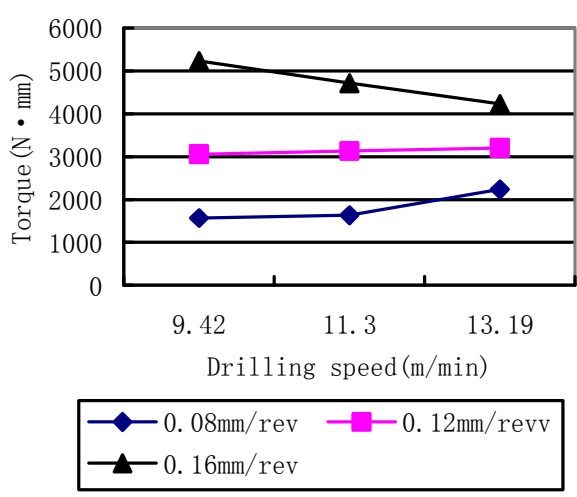

FIGURE XIV. VARIATION OF TORQUE WITH DRILLING SPEED FOR DIFFERENT FEED RATES. 


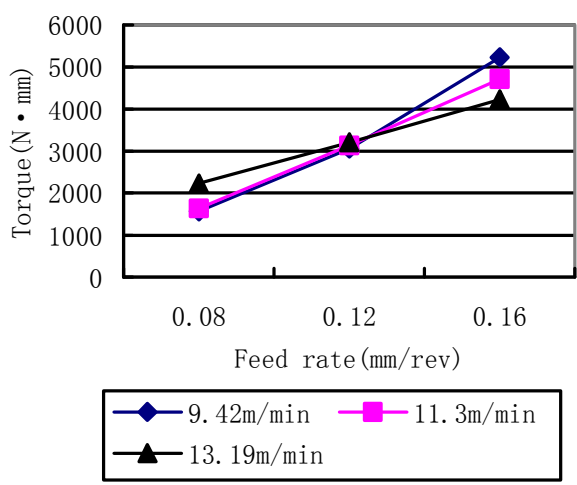

\section{FIGURE XV. VARIATION OF TORQUE WITH FEED RATE FOR DIFFERENT DRILLING SPEEDS.}

\section{CONCLUSIONS}

A 3D finite element model of drilling of titanium alloys is presented. A total of 9 simulations are performed to study the effect of drilling parameters on drilling performance. Simulation results suggest that feed rate has greater influence on the drill force, maximum tool temperature and drilling torque than drilling speed. In addition, based on the simulation results, the combination of low feed rate $(0.08 \mathrm{~mm} / \mathrm{rev})$ and high drilling speed $(13.19 \mathrm{~m} / \mathrm{min})$ is recommended for the drilling process of titanium alloys in order to obtain good machining performance and high productivity.

\section{ACKNOWLEDGEMENTS}

The author wishes to acknowledge with financial support of this research by National Natural Science Foundation of China under contract no. 51205177, Natural Science Foundation of Jiangsu Province under contract no. BK2012277, Natural Science Program for Basic Research of Jiangsu Province under contract no. 08KJB460002, Qing Lan Project, and Research Fund of DML-HYIT (HGDML-0901).

\section{REFERENCES}

[1] Klocke, F., Abouridouane, M., Gerschwiler, K. \& Lung, D., 3D modelling and simulation of gun drilling. Advanced Materials Research, 223, pp. 12-19, 2011.

[2] Guo, Y.B. \& Dornfeld, D.A., Finite element analysis if drilling burr minimization with a back up material. Proceedings of the XXVI NAMRC Conference, 1998; pp. 207-212.

[3] Guo, Y.B. \& Dornfeld, D.A., Finite element modelling of drilling burr formation process. Journal of Manufacturing Science and Engineering, 122, pp. 612-619, 2000.

[4] Isbilir, O. \& Ghassemieh, E., Finite element analysis of drilling of titanium alloy. Procedia Engineering, 10, pp.1877-1882, 2011.

[5] Lee, W.S. \& Lin, C.F., High-temperature deformation behavior of Ti6Al4V alloy evaluated by high strain-rate compression tests. Journal of Materials Processing Technology, 75, pp.127 - 136, 1998. 